\title{
Neurocomercio. una aproximación humanista para su fundamentación teórica
}

\section{Neuro-commerce. a Humanist Approach for its Theoretical Foundation}

\author{
Juan Diego Sánchez Sánchez \\ Universidad Nacional, Sede Central e Interuniversitaria \\ juan.sanchez.sanchez@una.cr
}

\section{Resumen}

El artículo presenta los conceptos y la esquematización teórica, conceptual y epistemológica referente a la estructura fundamental de la conducta comercial de los compradores de naturaleza física, así como los procesos que conllevan a la definición de sus decisiones de compra; muestra, a su vez, los temas atenuantes a la racionalidad y emotividad del consumidor desde un enfoque de carácter cerebral y neural, ligándolos de manera directa a los tópicos referentes al neuromarketing, el neurocomercio y a los procesos sinápticos dados en el individuo, estudiados desde una aproximación humanista integral en la concepción del hombre como un ser social y neural, lo cual permite detallar la relación existente entre los factores mentales y uso de regiones cerebrales de naturaleza inobservable que se dan en el cliente y su observación mediante el reflejo inductivo en la conducta comercial de las personas, detallada por parámetros de compra, de conducta y filosóficos del comercio, así como por una medición de indicadores enteramente de naturaleza comercial.

Palabras clave: Neuralidad, neural, neurocomercio, neuroconducta, neuromarketing, sinapsis, conducta del consumidor, conducta psicológica, humanismo. 


\begin{abstract}
This article presents the concepts and the theoretical, conceptual and epistemological scheme regarding the fundamental structure of the commercial behavior of buyers of physical nature, as well as the processes that lead to the definition of their purchase decisions. It also shows the attenuating topics to the rationality and emotional charge of the consumer from a brain and neural approach, directly linking them to the topics regarding neuro-marketing, neuro-commerce, and to the synaptic processes that take place in the individual, studied from an integral humanist approach in the conception of man as a social and neural being, which allows detailing the existing relationship between mental factors and the use of non-observable brain regions that occur in the client and their observation by means of the inductive reflex in the commercial behavior of people, detailed by purchase, behavior, and philosophical parameters of commerce, as well as by a measurement of indicators of an entirely commercial nature.
\end{abstract}

Keywords: Neurality, neural, neuro-commerce, neuro-behavior, neuromarketing, synapsis, consumer behavior, psychological behavior, humanism.

\title{
Introducción
}

Este artículo muestra las bases fundamentales de carácter teórico que definen el tema de la conducta neural del consumidor y plantea, para estos efectos, que la conducta comercial de un individuo suele ser evaluada, usualmente, por medio de los patrones de compra medibles y cuantificables; sin embargo, las características propias del individuo, en materia de su conducta neural, son dejadas de lado, entiéndase, por falta de una fundamentación teórica, o bien, por falta de un abordaje en términos humanísticos de la conducta neural del individuo, de forma que pueda ser evaluada y analizada desde una óptica del ser humano y no solamente como una unidad comercial generadora de datos y de riqueza, sino desde un punto de vista interno, en el cual sus procesos neurales definen en gran medida su conducta y logra así estructurar una posible definición de su patrón neural.

Los temas considerados en el trabajo responden al criterio de diferentes autores del área y consisten en la base para la aproximación teórica de la neuroconducta de la persona, así como el estado de la cuestión contemplado para el trabajo, desarrollado mediante la comparación de teorías existentes, criterios de autores y la descripción de los conceptos de relevancia que definen un concepto que tiene actualmente una relativa y escasa bibliografía. Esto permite en última instancia establecer conclusiones de carácter teórico que funjan como la base empírica en 
la definición de la conducta comercial de los individuos, así como su comprensión desde un punto de observación humano y no solamente de negocios. El objetivo central del artículo es definir las bases para la estructuración teórica de la conducta comercial, psicológica y neural del consumidor, desde una óptica humanista.

Planteada esta revisión de las diferentes hipótesis relevantes en el área, se procede a analizar dichos compuestos teóricos y se logra plasmar un punto de vista bibliográfico que permita estructurar los fundamentos del tema y detallar estructura teórica y analítica de la neuroconducta comercial del ser humano.

\section{Conducta del consumidor}

El consumidor es un ente racional e irracional quien, a su vez, es observable, según la teoría clásica de la conducta del consumidor, en función de sus comportamientos métricos y visibles (tanto en términos de sus compras) como de su efecto conductual en el comercio. Estos temas sostenidos por Schiffman y Kanuk (2005) y a lo que Mollá, Berenguer, Gómez, y Quintanilla (2006) detallan que la conducta del consumidor es "...el conjunto de actividades que realizan las personas cuando seleccionan, compran, evalúan y utilizan bienes y servicios, con el objeto de satisfacer sus deseos y necesidades, actividades en las que están implicados procesos mentales y emocionales, así como acciones físicas" (p.18).

Este tema particulariza, sin duda, que el consumidor es visto como una persona generadora de riqueza; sin embargo, este individuo, en términos específicos de su estudio en un concepto social, debe ser analizado como una unidad integral e integradora de un comportamiento determinado, el cual se liga a sus aspectos intrínsecos humanos, tanto de carácter emotivo y racional y reflejados en su patrón neural, como en su personalidad, cuestión definidora directa de la conducta humana en materia de comercio.

En este punto cabe resaltar la diferencia entre consumidor y usuario final. El primero corresponde a la persona que compra el producto y que genera esta conducta medible definida previamente, mientras que el usuario final es la persona que hace uso del producto (Solomón, 2013). Ambos pueden ser la misma persona o distintas en algunos casos. Para este trabajo, el consumidor se define como el individuo comprador.

Otro elemento de importancia en la conducta del consumidor es la personalidad intrínseca de cada individuo, la cual consiste en los rasgos, las características, las 
creencias y los elementos individuales adyacentes a cada persona y que definen precisamente la identidad racional y emocional del individuo (López y

Pérez-Llantada, 2005), lo que da pie a indicar que la conducta de la persona es definida, en gran parte, por su capacidad de generar emociones y razón en sus procesos cognitivos, lo cual tiene origen en la generación de la actividad neural y da pie a las decisiones humanas que permiten, a su vez, analizar a la persona como un individuo social y no solamente como una unidad comercial en un proceso de negocios.

Con base en lo anterior, se plantea la existencia de diversas personalidades en los consumidores, por lo que la decisión de compra y la conducta comercial de los clientes está en función directa de la personalidad. El tema logra observarse de forma clara en lo expresado por Clonninger (2003), quien sostiene que la personalidad es entendida como: “...las causas internas que subyacen al comportamiento individual y a la experiencia" (p. 25). Se señala en este punto que dichas causas hacen referencia, precisamente, a los factores neurocognitivos de la persona, los cuales sin duda moldean y definen la conducta comercial de los hombres y de las mujeres.

El concepto de la personalidad también hace referencia a la racionalidad y emotividad de las personas, puntos que definen en gran parte el comportamiento comercial, las decisiones de compra y las posibles acciones de respuesta en la gestión comercial de las empresas, aspectos que encuentran cabida en las ideas expresadas por Clonninger (2003), quien plantea precisamente la relación entre los elementos mencionados y las decisiones finales de compra del cliente.

El tema se observa también en los puntos expresados por Schiffman y Kanuk (2005) quienes indican que esta conducta:

...se enfoca en la forma en que los individuos toman decisiones para gastar sus recursos disponibles (tiempo, dinero y esfuerzo) en artículos relacionados con el consumo. Eso incluye lo que compran, porque lo compran, cuando lo compran, donde lo compran, con qué frecuencia lo compran, cuan a menudo lo usan, cómo lo evalúan después... (p. 8).

Puede definirse entonces que la conducta de compra de un bien o servicio se basa principalmente en dos factores: la conducta psicológica propia del individuo y la conducta de compra de la persona, es decir, en los elementos personales y del comercio, señalando que la persona debe ser vista desde una perspectiva humanística y no solo lucrativa, tópicos que se explican posteriormente. 


\section{Conducta psicológica}

Tal y como se indicó, los consumidores son evaluados en su mayoría por la rentabilidad que aportan a la empresa, en términos de sus movimientos de compra y de lucro (Keat \& Young 2004); sin embargo, esto no implica que no presenten una conducta mental que demuestre su comportamiento psicológico, definida por otras variables de carácter social y personal, contraponiendo así la teoría económica tradicional que indica que el individuo actúa de forma racional en su consumo, y da pie al juego de pesos y contrapesos emotivos y racionales en la persona, lo que a su vez puede ligarse de forma directa a la naturaleza neural de la persona (López y Pérez-Llantada, 2005) y que debe ser estudiada como un elemento subyacente al comportamiento individual de cada particular.

Dicha conducta puede observarse en las ideas expuestas por Schiffman y Kanuk (2005), quienes en relación con la segmentación psicológica señalan que:

.... se refieren a las cualidades internas o intrínsecas del consumidor individual. Las estrategias de segmentación del consumidor a menudo se basan en variables psicológicas específicas. Por ejemplo, los consumidores pueden distribuirse en segmentos de acuerdo con sus motivaciones, personalidad, percepciones, aprendizaje y actitudes (p. 60).

Se mencionan aspectos inobservables de mayor dificultad en su medición, tema que se contrapone lo señalado en los conceptos básicos del mercadeo y el comercio, que señalan la relevancia de que toda conducta sea evaluada y cuantificada en términos de ganancias (Keat \& Young, 2004); sin embargo, esto no indica que no puedan ser medibles y analizados mediante procesos de investigación social, mediante la observación y el análisis de procesos inductivos de la conducta comercial de los individuos (García, 2005), puntos que permiten determinar los elementos de carácter subjetivo y social que faculten un estudio del consumidor como un ser social en un entorno humanístico y psicológico y no solamente como un dato de compra, sino más bien como un ser humano integral.

Se establece entonces que la conducta psicológica de los consumidores consiste en la sumatoria de todos los factores mentales que definen y dan forma a las decisiones de compra y a las actitudes comerciales existentes, ideas que se sustentan en lo expresado por Mollá et al. (2006). Ellos plantean precisamente que son los elementos intangibles y de naturaleza mental los que terminan definiendo la conducta comercial y dan forma a los elementos etéreos de las decisiones comerciales de adquisición de un determinando bien o servicio y que tienen su origen en los procesos mentales conscientes e inconscientes de la persona, tal 
como lo establece Thayer (1998), generadores a su vez de los estados de ánimo que estructuran de igual forma la conducta humana. Estos estados, como se definen luego, se ligan directamente a la generación de la actividad cerebral, neural y sináptica en las personas, factores que definen de forma directa las emociones y las decisiones racionales de las personas, puntos establecidos por Sutil (2013). Se demuestra entonces que la conducta psicológica de las personas, aunque pareciera tener una medición y evaluación complicadas, puede ser hallada en la generación de la actividad neural, la cual puede perfectamente establecer supuestos teóricos sobre ciertas áreas cerebrales a determinadas conductas humanas.

Adicionalmente, pueden considerarse como factores claves de la conducta psicológica aspectos como las percepciones, las ideas, los factores motivacionales, la capacidad analítica, las creencias, los valores y demás elementos de la personalidad (Clonninger, 2003); dichos temas definen de forma directa la manera de comportarse las personas en el ámbito comercial.

Por ello se establece que toda conducta comercial se deriva de elementos de índole psicológico, los cuales se fundamentan en temas motivacionales, racionales y emotivos, de difícil medición y explicación, pero que encuentran sustento y respuesta en la generación y activación de la neuralidad en las personas y definen de forma directa las decisiones de compra, las cuales, a su vez, responden a un entorno social de la persona.

\section{Conducta comercial}

Es la psique del ser humano, desde una óptica de ente consumidor de productos y servicios, la que define sus patrones conductuales y, por ende, su toma de decisiones en el ámbito del comercio, tal y como lo aseguran Schiffman y Kanuk (2005).

Por ello es necesario llevar a cabo un correcto análisis de las variables, tanto psicológicas como comerciales, ya que son estos dos factores los que finalmente definen y estructuran la conducta de compra del individuo; se resalta nuevamente la importancia de que el ser humano no sea visto en el comercio como una simple unidad comercial, sino más bien como un ser integral, al considerar su psicología como un factor determinante en la definición de la neuroconducta.

En el concepto anterior se observa claramente la importancia de la medición de las variables comerciales, tales como los tiempos de compra, los precios y demás comportamientos pre y postventa, factores que son medibles por medio de métricas previamente establecidas, tal y como lo manifiestan Domínguez 
y Muñoz (2010), de forma que se cuente con la información necesaria para la toma de decisiones. Estas variables demuestran la naturaleza comercial del individuo; sin embargo, cabe cuestionarse en este punto ¿dónde quedan los factores conductuales humanos? que en ocasiones suelen ser inexplicables; la respuesta subyace no en la conducta observable, sino más bien en un submundo de categorización neural, escondido en la mente del cliente, el cual debe ser analizado tanto desde una aproximación humana, como desde un punto de vista comercial, definiendo así la decisión neural de compra comercial como un tema humano-comercial.

Por otra parte y en términos de investigación comercial y social, Malhotra (2004) sostiene que la conducta comercial hace mención al reflejo de las decisiones de compra que el cliente lleva a cabo en cualquier proceso de compra y venta, reflejado en sus patrones de compra que presenta una naturaleza cuantitativa y observable, ya que permite su evaluación mediante una serie de mediciones estadísticas y econométricas (Hernández, 2007) que facultan a la empresa a influir dicha conducta, así como a observar si lo adquirido por el consumidor es lo deseado originalmente $y$, por ende, lo satisface.

Esteban et al. (2002) plantean dicha relación y señalan, por extensión aplicable a la neuroconducta, la preponderancia de que los patrones de compra cuantificables sigan siendo evaluados. Se sugiere agregar la gestión y evaluación de los elementos subyacentes neurales y humanísticos del individuo comprador de productos, de forma que el ser humano comprador sea visto como un ente integral y cuyas decisiones de compra sean consideradas desde una aproximación social, al lograr que la explotación lucrativa no sea el eje fundamental, sino más bien que logre dignificarse a la persona, respetar y entender sus decisiones de compra, lo que se logra por medio de la evaluación de los factores subyacentes del comprador.

Por último y siempre en relación con la medición de la conducta comercial de compra en el consumidor, debe definirse claramente que aunque la psique humana presenta dificultad de medición, según establecen Gerrig y Zimbardo (2005), relativo al tema de la conducta comercial y sus indicadores cuantitativos, se ve reflejada en las decisiones de compra del individuo y, por ende, en los patrones de compra (Johnston y Marshall, 2009), lo que brinda una posibilidad real de evaluar cuáles variables comerciales representan una mayor influencia en la compra y permiten la evaluación, por inferencia e inducción (Babbie, 2000) de la conducta psicológica; es decir, por un análisis en el que se comparen las compras del cliente en relación con el nivel de análisis que realiza en sus compras, así como los factores que las influencian. 
De esta manera, se define que la conducta comercial es una especie de sumatoria entre la psicología humana, su entorno personal y social y su conducta subyacente neural, pero en este caso particular, ligados de manera directa a la generación de pesos y contrapesos analíticos y emotivos, enfocados en la decisión final de adquirir o no bienes y servicios. Hay que resaltar de manera especial que la conducta es propia e inherente al hombre, de forma que debe ser considerada como un concepto humanístico y no solamente comercial, que dignifique al hombre y en la que el comercio debe ser estudiado como una herramienta de carácter beneficioso y social para el ser humano. Según lo expresan Santacolama y Aguado (2011), lo anterior no implica desde ninguna circunstancia que se descuide la generación de riqueza.

\section{Decisión de compra}

Corresponde a la ecuación fundamental de comprar y adquirir un bien o servicio, dada por los elementos racionales y emotivos del consumidor (Sánchez, 2011), definida como:

...el reconocimiento de un problema o necesidad no satisfecha por parte del consumidor, continúa con la búsqueda de información, así como la evaluación de diferentes soluciones que se puedan plantear, culmina con la compra del producto y finaliza con la valoración de si el producto comprado ha resuelto el problema que inició todo el proceso (Esteban et al., 2002, p. 82).

Puede destacarse que el concepto de decisión de compra hace referencia a la decisión final que el cliente toma y que lo hace elegir un determinado producto.

Estas ideas encuentran sustento en los temas expuestos por Grande y Alonso

(2004), quienes además plantean la influencia que los elementos personales tienen en el consumidor, especialmente, aquellos que definen y moldean su personalidad y su conducta y destaca entre ellos sus procesos mentales, valores, creencias y percepciones, entre otros.

Siempre en relación con la decisión de compra, puede definirse que la ecuación de compra simple se establece por la relación de $\mathrm{DC}=\mathrm{RC}+\mathrm{MC}$, donde $\mathrm{DC}$ significa la decisión de compra, RC la razón de compra y MC motivo de compra, donde la razón es el elemento analítico y racional, tal y como lo sostienen Grande y Alonso (2004). El motivo es el factor emotivo, siendo a su vez el elemento irracional del comprador, factores que definen el tipo de decisión de compra, sea 
esta racional o emotiva, o bien una mezcla de ambas y en función de sus pesos porcentuales. Desde este principio ecuacional, pueden plantearse decisiones dicotómicas, las cuales son completamente emotivas o racionales, o politómicas, donde se da una mezcla de ambos elementos, y se inclinan hacia alguna dirección, según sean politómicas emocionales o politómicas racionales. En caso de que sea igual el porcentaje entre ambas, la decisión se conoce como politómica perfecta.

Es importante hacer referencia a la mezcla entre la racionalidad y la emotividad del cliente en el establecimiento y la estructuración de sus decisiones comerciales:

- Por una parte, Thayer (1998) sugiere que el ser humano, en función de su conducta, no solamente es un ente social, sino que presenta elementos racionales y emocionales definidores de sus decisiones, temas que pueden ser aplicables, de igual manera, al comportamiento de compra (Schiffman y Kanuk, 2005).

- Por otra parte, Flavian y Gurrea (2003) aseguran que los pesos porcentuales en cada elemento varían dependiendo tanto de la persona, como del entorno y del bien en cuestión, donde la decisión de compra cambia en su naturaleza intrínseca y cae en un juego de pesos porcentuales emotivos y racionales, lo que nuevamente demuestra que la decisión comercial de la persona es un juego de elementos de carácter emocional y racional, atenuantes a un comportamiento enteramente humano, que definen su decisión final, dados a su vez de manera neural.

La compra no escapa a dicha situación (Braidot, 2009); sin embargo, este concepto debe ser visto como un proceso humano, puesto que las compras en esencia consisten en la adquisición de bienes y servicios para solventar necesidades y deseos, de manera que puede definirse que la decisión de compra es, a su vez, un proceso de carácter humanista que tiene un elemento psicoemocional y cognitivo en su desarrollo y que debe tener la función fundamental de beneficiar al ser humano y no de explotar su comportamiento en aras de maximizar una ganancia; se obtiene así que un proceso de venta con carácter humanista tiene, incluso, mejores resultados, sobre todo en términos de solidaridad comercial (Santacolama y Aguado, 2011).

Definidos los temas relacionados con la conducta del consumidor y sus elementos básicos, se explican a continuación los conceptos del neurocomercio. 


\section{Neuromarketing}

Si bien es cierto en el enfoque de la teoría conductista del consumidor, el elemento mental y las percepciones del consumidor no son medibles ni evaluables de forma objetiva, en términos más contemporáneos, se observa la aplicación de la teoría del neurocomercio y el neuromarketing (Braidot, 2009), factores que denotan un estudio de los procesos neurales y mentales del consumidor y la repercusión que tienen en su accionar comercial de compras.

Para estos efectos, es necesario plantear que el neuromarketing se entiende como:

El estudio del mercado desde la óptica del neuromarketing, con la ayuda de moderna tecnología como la resonancia magnética y la tomografía computarizada, permite conocer mejor las sensaciones que le producen placer al consumidor y por lo tanto encontrar los satisfactores más adecuados para él (Malfitano, Arteaga, Romano y Scínica, 2007, p. 22).

Para este tema se plantea la importancia del estudio del consumidor, no solamente como un ente de naturaleza comercial y en función del reflejo de sus decisiones de compra, si no que establece la relevancia del estudio de la persona compradora como un ser mental y con una naturaleza subyacente neural, donde sus decisiones son el reflejo de complejos procesos neurales en el que las regiones cerebrales y las diferentes relaciones neurales son de suma relevancia. Estos conceptos son expuestos por Renvoisé y Morín (2006) quienes, a su vez, plantean la importancia de que estas variables sean estudiadas a fondo para lograr descubrir las verdaderas razones de la compra y la conducta comercial de los consumidores en función del comportamiento cerebral. Puede definirse que la conducta humana es un reflejo directo de la actividad cerebral generada en la persona y es un concepto que, a su vez, repercute en un patrón conductual ligado al comercio, el cual desde este enfoque debe sustentarse en un comercio sostenible y de beneficio a la persona.

El tema en cuestión se observa en lo expuesto por Braidot (2009), quien plantea la idea de que:

En las sociedades modernas, las preferencias que inciden en la elección de distintas comidas o bebidas tienen su origen en una modulación de variables sensoriales, estados hedónicos (de placer), expectativas, motivaciones, priming semántico y se hallan influidas también por las construcciones que emergen del contexto cultural. Mediante pruebas experimentales, se comprobó que estas preferencias pueden detectarse mediante la lectura de las ondas cerebrales del individuo expuesto a los mismos estímulos y también mediante neuroimágenes (p. 80). 
El término de priming semántico se refiere al factor con el cual una persona o un cliente asocian una marca o producto a un concepto y en términos de su recordación.

Es así como el neuromarketing estipula la importancia de enfocarse más en un comercio tradicional de enfoque lucrativo puro y simple de ventas, tal como lo exponen Johnston y Marshall (2009), hacia la conversión del neurocomercio, donde se identifiquen las áreas de naturaleza mental y de reacción neural que definen la decisión de compra (Malfitano et al, 2007). Lo anterior permite plantear que el neurocomercio debe evaluar las decisiones humanas comerciales, que son a su vez un resultado directo de la actividad cerebral de la persona.

Esta rama comercial estudia al ser humano en su entorno y lo considera a su vez como un ser integral e individual simultáneamente, donde sus procesos neurales son dados por decisiones totalmente individuales y según el funcionamiento de su cerebro, lo que da paso a establecer una teoría dualista en la definición de la conducta neural del consumidor, fundamentada en una integralidad social, ligada a su vez a una neuralidad individual, que desde un enfoque humanista son considerados como temas propios del hombre y que deben ser gestionados en aras de dignificar y beneficiar a la persona.

Puede señalarse que para este tipo de estudios las mediciones electrónicas, por medio de herramientas tecnológicas, se tornan de suma relevancia ya que, según Braidot (2009), el cliente puede decir algo pero los procesos neurales que ocurren en su mente reflejan una realidad completamente diferente a lo que expresa, de forma que destaca aún más la relevancia de considerar al ser humano consumidor como un ente dualista en términos de sus decisiones comerciales, lo que sugiere que su estudio debe darse tanto de forma cuantitativa como cualitativa y desde un punto de vista comercial, pero sin descuidar la aproximación social de la venta.

Si bien es cierto las mediciones neurales electrónicas, entiéndase las tomografías computarizadas (Braidot, 2009), son de suma relevancia para el estudio del neuromarketing, no son la única manera de realizar su medición ya que si se utiliza un proceso investigativo de lógica deductiva (Babbie, 2000), en el que se determine cuáles herramientas comerciales presentan una mayor influencia en el consumidor y logran generar las respuestas que el individuo da a su aplicación, puede observarse un proceso inductivo de investigación o incluso de naturaleza inferencial (López, 2006), en el cual se plasma que el estudio neuroconductual define a la persona como un ser humano guiado por su neuralidad hacia un proceso estructurado de toma de decisiones, basado en procesos de carácter subyacente e inobservable en un simple patrón conductual cuantitativo. 
Quizás el ejemplo más claro se da en el caso de la publicidad, en el que dependiendo de la naturaleza del mensaje (racional o emotivo) se presentan movimientos en ventas, lo cual permite inducir el comportamiento neural del individuo.

Domínguez y Muñoz (2010) establecen la validez del uso de una métrica correcta, aunque esté basada en la observación, tema que puede ligarse al estudio de la conducta resultante de la aplicación de una variable comercial a un determinado grupo de consumidores. Por tratarse de estudios enfocados en la neuralidad de la persona, los resultados comerciales son mejores cuando el enfoque que se aplica responde a una naturaleza humanista, en el que se busque como fin último la comprensión real de los motivantes neurales y definidores de la decisión de compra de la personas y no solamente la simple venta, al lograr así entender al individuo $\mathrm{y}$, por ende, beneficiar su misma existencia por medio del neurocomercio.

Se observa claramente la influencia que los procesos mentales y neurales tienen en las decisiones de compra de los consumidores y en sus regiones cerebrales, las cuales se explican a continuación.

\section{Regiones cerebrales}

Los procesos mencionados encuentran su funcionamiento en las regiones cerebrales del individuo, en este caso, en las del consumidor., detallándose tres cerebros, división definida en función de las capas cerebrales donde, según Braidot (2009), se presentan las regiones reptiliana, límbica y neocortesiana o el neocortex. La primera capa del cerebro presenta un manejo instintivo e impulsivo del comportamiento cerebral, la región límbica maneja las emociones del ser humano y, por último, el neocortex se encarga de los procesos analíticos $\mathrm{y}$ racionales del hombre.

Esta separación de capas cerebrales se observa en lo expresado por Braidot (2009), quien plantea que:

Durante el transcurso de millones de años de evolución, en el cerebro humano se han presupuesto progresivamente tres niveles que funcionan de manera interconectada, cada uno de ellos con sus características específicas. Estos niveles se conocen como sistema reptiliano, sistema límbico y córtex o cerebro pensante (p. 23).

Se observa claramente una estructuración específica del comportamiento humano en función de los cerebros utilizados por el hombre en su generación de conducta. Estos conceptos se explican a continuación. 


\section{Cerebro reptiliano}

El primero y el cerebro más primitivo del ser humano (Braidot, 2009) es definido como el reptiliano, sección cerebral que controla y ejerce todas las funciones relacionadas con los instintos del ser humano. Se encuentra localizado en el interior del cerebro total, es decir, en el centro del cráneo humano.

Es precisamente en esta sección cerebral donde se generan las compras instintivas e impulsivas, lo cual constituye un factor decisor de gran peso para la toma de decisiones comerciales en las que no se genera ningún proceso analítico.

\section{Cerebro límbico}

El segundo cerebro que influye en las decisiones de compra del ser humano es el límbico, región que domina y controla los procesos ligados a las emociones (Malfitano et al., 2007). A su vez, en el punto generador de los factores irracionales y emotivos en las decisiones de compra, de manera que precisamente este cerebro es el que debe ser influenciado por las campañas comunicacionales o comerciales que se enfocan en temas de naturaleza emocional, concepto que encuentra cabida en las ideas expuestas por Braidot (2009).

\section{Cerebro neocortesiano}

Por último, se presenta la región cerebral conocida como el neocortex o el cerebro neocortesiano, región que controla los procesos analíticos y de raciocinio del ser humano (Sutil, 2013), es decir, las situaciones que requieren un mayor grado de análisis y pensamiento en una determinada decisión. Este tema aplica también para las decisiones comerciales de los individuos. Renvoisé y Morín (2006) indican la relevancia de la racionalidad en la formación de criterios y decisiones de la conducta humana.

También Braidot (2009) señala que aquellos factores que apelan a una racionalidad implícita en los procesos de compra se enfocan en el neocortex (es decir, el uso de campañas o tácticas comerciales o de comunicación que se liguen a temas de naturaleza racional parecen influir, de manera directa, en el uso de la capacidad analítica del comprador, mientras que las herramientas comerciales de impacto emotivo o con mensajes en esa línea generan un impacto mayor en la capacidad límbica del consumidor y apelan a una naturaleza emocional que, a su vez, se liga de forma directa a una disminución en la capacidad analítica, tal y como lo establece Sánchez (2011), quien sostiene, además, que las emociones presentan un 
comportamiento distinto de la razón y generan un efecto alejado de la capacidad cognitiva e incluso del raciocinio en las personas.

En este punto puede observarse una sencilla explicación desde la óptica humana del consumidor, en la que se establece que los elementos de carácter emocional parecen tener más peso en la generación de respuestas en la persona, puesto que tiende a tener un ligamen mayor al cerebro límbico y, por extensión, a una generación responsiva en la psique, mientras que la racionalidad requiere un mayor procesamiento y, por ende, las respuestas en el consumidor son retardadas. Este tema aborda un enfoque casi anfibológico en la contemplación de la conducta humana de compra y refuerza el concepto de que este estudio neuroconductal de la decisión comercial en las personas debe ser visto desde un punto de vista humanista y social y no solamente como un simple proceso económico y comercial.

El tema encuentra también cabida en el concepto del humanismo empresarial, definido por Luelmo (2012) como aquel enfoque comercial que:

...consiste en una pequeña medida, en la toma de conciencia por parte del empresario de que organizar la complejidad social no es una mera operación de desarrollo de sistemas más eficaces de rendimiento humano. (...) como crear un estilo humano de vida, que incluya el interés básico por lo económico, pero que no coloque a todo el mundo bajo la primordial obsesión de vivir para producir más rentablemente. Porque sin duda, además, una rentabilidad que no se apoya en la superioridad del espíritu, se muestra a la larga como engañosa. (p. 29)

Puede determinarse que la contemplación del espíritu o del bien social, en el contexto empresarial, es aplicable al neurocomercio, pues la mejor manera de dignificar al hombre es precisamente por medio de la comprensión y el entendimiento a fondo de su actividad mental, lo cual denota la relación existente entre este tipo de comercio y el enfoque humanista.

Por otra parte, en una división adicional del cerebro y ligada a los conceptos de racionalidad y emotividad, se tiene la definición tradicional entre hemisferio derecho e izquierdo, donde Braidot (2009) plantea que el primero atañe a la parte creativa y emocional del ser humano, mientras que la segunda a las relaciones analíticas y cognitivas del hombre, donde el lóbulo frontal del cerebro administra el uso del sentido común y de la razón. 
Los temas señalados se observan en lo expresado por Renvoisé y Morín (2006), quienes sostienen que:

Las emociones incluyen a menudo lo que llamamos instinto o intuición. A pesar de que muchos de nosotros hemos sido enseñados a seguir nuestra cabeza, dominada por la lógica de la parte izquierda del cerebro, las investigaciones han demostrado que estamos más inclinados a seguir nuestro corazón. Existe una fuerte conexión entre la parte derecha de nuestro cerebro, emociones y el impacto que recibe el CEREBRO PRIMITIVO (p. 154).

Precisamente el hemisferio derecho es el que controla y en el que se llevan a cabo todas las expresiones humanas relacionadas con la emotividad y creatividad, mientras que su contraparte, el hemisferio izquierdo, administra las experiencias y la razón. De esta manera, se presenta una especie de dicotomía metafísica entre la naturaleza mental del hombre, lo cual indudablemente repercute en su personalidad y su autodefinición (López y Pérez-Llantada, 2005).

Esta es quizás la división cerebral más tradicional; sin embargo, no deja de denotar un punto de estudio interesante, ya que la vista humana tiene un funcionamiento inverso a ambos hemisferios descritos y el ojo izquierdo se liga al derecho y viceversa (Sutil, 2013). Este tema permite definir un supuesto teórico en el que se enuncia que una imagen o pieza gráfica que desee apelar a un enfoque neuroconductual emotivo debe ser diagramada de tal forma que se aprecie y genere mayor impacto por el campo de visión occidental del ser humano, o bien, un elemento racional, con una relación opuesta, ¿es posible generar emociones humanas con tan solo un uso adecuado de las imágenes? Aunque el tema pareciera bastante complejo, este simple supuesto ligado a la neuroconducta humana pareciera indicar que sí puede afectarse el comportamiento por medio del uso de imágenes y establecer líneas de control e incluso permitir el cuestionamiento ético de dicha manipulación neural de las personas.

Lo anterior da paso a indicar que una aproximación administrativa de la conducta humana en la que se participe y se tenga un contacto humano más directo con el consumidor parece tener más afectación que la simple generación de medios masivos, lo que permite estipular que la venta neural trabajada desde un enfoque humanista de trato personalizado y de carácter social repercute en mayores resultados monetarios y de lealtad para las empresas, por lo que este enfoque debe ser considerado como prioritario en las estrategias comerciales, en especial, en las que se cuente con contactos más directos hacia los consumidores. 


\section{Sinapsis neural}

Cubiertos los temas referentes a los cerebros o regiones cerebrales, relacionados con los comportamientos de compra en el consumidor, es necesaria la explicación de otro elemento de suma relevancia en la conducta neurocomercial, denominado sinapsis neural, que según Anderson (2008) consiste en la relación entre neuronas en el cerebro humano, donde dicha relación se da mediante el intercambio de impulsos electromagnéticos y por la transmisión de comunicación entre ellas.

Por otra parte, la sinapsis neural implica el movimiento de neurotransmisores tales como la serotonina, acetilcolina, endorfinas, dopamina, norepinefina y otros (Pardo, 2013). Consiste en un complejo sistema de redes neurales presentes en el cerebro del individuo, tema que dificulta su estudio, tal y como lo asegura Chaves, citado por Pardo (2013), quien indica que:

...es infinitesimal lo que conocemos del cerebro hasta el día de hoy. Como factores que han dificultado esa mayor aproximación, cita sus complejas redes neuronales y el hecho de que las funciones cerebrales no están localizadas en un sitio en particular, sino que son producto de las activaciones de ese entramado de redes. (párr. 14)

$\mathrm{Al}$ respecto, se presentan tres diferentes connotaciones de la sinapsis neural: la presinapsis, la sinapsis tal cual y la postsinapsis, las cuales se explican a continuación:

\section{Presinapsis}

En este punto se da una impresión únicamente neural; es decir, no se presenta una comunicación entre neuronas, sino más bien un primer contacto neural (Braidot, 2009). El proceso analítico dado en el cerebro para este caso no presenta mayor desarrollo y puede definirse como un proceso de impresión, tal y como sugiere Anderson (2008).

Los impulsos y las primeras impresiones se definen en este estado sináptico. Se observa a un ser humano casi de naturaleza instintiva y de poca racionalidad, Esto sugiere que los consumidores que no razonan parecieran ser movidos por los impulsos, por lo que en términos comerciales, en el corto plazo, debe explotarse esta etapa sináptica, claro está, si lo que desea explotarse es el elemento lucrativo, el cual no necesariamente debe entenderse mutuamente excluyente del enfoque humanista del comercio, puesto que tampoco indica que se dé un impulso generado por manipulación o algo similar. 


\section{Sinapsis}

La sinapsis, según Anderson (2008), consiste en que "cada neurona tiene su propia membrana y está separada de las otras. La información fluye de una a otra a través de las sinapsis, que le permiten a una neurona influir en otras" (p. 31). Representa básicamente la comunicación entre neuronas cerebrales que permiten que el ser humano plantee un proceso analítico en su cerebro. Se sugiere que el individuo reciba, procese y razone en relación con la información absorbida $y$, a su vez, logre establecer decisiones de carácter más racional que le permitan generar una conducta basada en la razón, aunque sin un análisis profundo, de forma que no necesariamente implica que la conciencia del ser humano es activada en este enfoque y, por ende, sus decisiones comerciales no parecen plantear un razonamiento estructurado a fondo.

\section{Postsinapsis}

Por último, se presenta el proceso postsináptico, el cual se da después de la sinapsis neural y consiste en el análisis y la comunicación con mayor profundidad entre las neuronas cerebrales (Anderson, 2008), el cual permite a la persona crear un proceso de raciocinio mucho más estructurado.

Para este último estadio sináptico, la persona establece un proceso a fondo y totalmente estructurado en relación con sus decisiones de compra y una conexión fuerte entre neuronas, tal y como lo establece Jensen (2004). La conducta del individuo en este punto es sustentada en un proceso en el que la conciencia y el análisis racional toman un papel preponderante y pareciera tener un enfoque mayormente humanista en el sentido que se logra explotar todo el potencial analítico del hombre en relación con su conducta comercial.

Con base en las definiciones planteadas, puede establecerse una relación lógica en términos de los procesos sinápticos y del uso de las regiones cerebrales. El uso del neocortex pareciera estar estrechamente ligado a un proceso postsináptico $\mathrm{y}$, por ende, a un enfoque analítico a fondo, en la toma de decisiones, por parte de los consumidores, al sustentar un uso racional de su capacidad decisora en la adquisición de productos, tema reforzado en lo expuesto por Sánchez (2011).

Por otra parte, se establece una estrecha relación en cuanto a los procesos presinápticos del individuo y la generación de actividad cerebral en la región límbica, lo cual denota un enfoque emotivo en la estructuración de las decisiones de compra y, por ende, una mayor actividad emocional que se contrapone a los 
procesos analíticos y racionales, tema que a su vez encuentra cabida en las ideas planteadas por Renvoisé y Morín (2006), quienes sostienen que el factor emotivo en las compras tiene una gran injerencia en la toma de decisiones e incluso tiende a ser más fuerte que los procesos racionales en el consumidor.

El concepto del estudio humanista puede ser aplicado en ambos casos, puesto que para una decisión de carácter racional, el individuo explota toda su capacidad cognitiva y alcanza un estado de conciencia pura en el que se revela todo su potencial, mientras que para el enfoque emotivo, el hombre consumidor es dignificado en función de la explotación de sus emociones.

\section{Neurotransmisores}

Otro aspecto relevante son los neurotransmisores, conocidos también como neuroquímicos en el cerebro humano, tema sostenido por Pardo (2013), quien señala además que la relación dada para estos químicos cerebrales no es otra cosa que su tránsito por las neuronas cerebrales, lo cual genera las diversas emociones en el ser humano de manera casi instantánea, punto que permite definir que las emociones corresponden a la correcta y específica mezcla de químicos en el cerebro. Sin duda, esto podría sonar como una definición tosca de las emociones humanas; sin embargo, neuroconductualmente encuentra su sustento en estos químicos, por lo que para su investigación es necesario un estudio comercial y neural simultáneo de una persona.

Según Pardo (2013), algunas de las emociones relevantes en el estudio neurocomercial del ser humano son:

- Amor $=$ dopamina + serotonina + oxitocina. Esta mezcla genera endorfinas, que hacen que la racionalidad sufra una caída considerable.

- Furia o temor $=$ noradrenalina + adrenalina. Esta sensación puede entenderse como la respuesta racional a una situación desconocida.

- Depresión = mínimos de serotonina y dopamina. Para esta emoción resaltan temas como tristeza, lástima, entre otros.

- Felicidad = serotonina. Esta situación sopesa cualquier proceso racional en la persona.

- Esquizofrenia = máximo de dopamina. Lo curioso de esta emoción es que es dada por un 33\% del neuroquímico que genera el amor. 
Es así como puede definirse el fundamento teórico de que las emociones son mezclas estructuradas de químicos cerebrales, influenciables por el correcto uso de técnicas comerciales. Concepto que permite plantear la idea de que en el comercio es posible moldear a voluntad las emociones humanas, repercutiendo en la generación de actividad cerebral y, por ende, influenciar las decisiones comerciales de las personas.

\section{Herramientas neuropsicológicas comerciales}

Si bien es cierto la conducta comercial del consumidor es un elemento relacionado con la naturaleza individual de las personas y no es controlable de manera directa, las empresas pueden hacer uso de diversas herramientas o tácticas que les permiten administrar y gestionar de manera efectiva las ventas, tal y como establecen Johnston y Marshall (2009), lo que influye de forma directa en los patrones de conducta de compra y, por ende, incrementa las transacciones comerciales con los clientes, además de establecer métricas de carácter cuantitativo (López, 2006) que permitan evaluar a fondo las conductas humanas.

Para estos efectos puede plantearse que las empresas deben definir sus herramientas comerciales en función de la conducta de sus clientes y enfocarlas en términos de los resultados que deseen lograr, es decir, planteando enfoques emotivos o racionales (Clonninger, 2003) y generando cambios de las transacciones de venta. Estos elementos permiten observar el efecto o el resultado de la conducta neural de los individuos, reflejado de forma directa en las compras dadas en el cliente e influenciadas por el uso previo de la herramienta controlable, siempre con el sustento de la exploración inductiva del comportamiento humano y neural del individuo en función de sus regiones cerebrales utilizadas, así como su sinapsis (Jensen, 2004).

Las herramientas o tácticas de naturaleza neuropsicológica en los negocios pueden definirse como las variables internas y controlables, enfocadas a la promoción, publicidad, precios, servicio, distribución, productos y demás elementos de naturaleza comercial (Mollá et al., 2006) que permiten influenciar de forma directa las actitudes y los patrones conductuales de compra de los individuos consumidores de las empresas. Los conceptos tratados en este punto se reflejan cuando, en relación con el uso de herramientas de influencia comercial, se indica que:

Este plan sabemos que debe contener el conjunto de decisiones relativas a las herramientas o variables de marketing utilizadas en cada situación. Resulta incomprensible pensar que puedan tomarse decisiones comerciales sin partir de alguna formulación de hipótesis en torno al funcionamiento de los intercambios 
$\mathrm{y}$, concretamente, en torno al comportamiento de los consumidores. (Grande y Alonso, 2004, p.28)

Los elementos del consciente y del subconsciente del consumidor hacen referencia a las decisiones que el individuo toma en función de sus compras (Malfitano et al., 2007). Estos temas son observables en el comportamiento individual de cada persona, aspecto que refleja la psicología interna del hombre, tal y como lo sostienen Gerrig y Zimbardo (2005).

Un ejemplo de esto se da en el caso de la creación de un mensaje de naturaleza racional o una promoción que apele al análisis del cliente, la cual, en caso de aumentar las ventas, puede observarse claramente un uso neocortesiano del cerebro (Braidot, 2009) y un proceso postsináptico (Anderson, 2008) o bien, en caso contrario, el incremento en ventas dado gracias a una campaña comunicacional publicitaria, cuyos elementos primordiales sean conceptos ligados a factores emocionales que más bien busquen la minimización de los procesos analíticos en el consumidor, tema sostenido por Sánchez (2011), quien detalla esta relación en el uso de herramientas comerciales y menciona la racionalidad y emotividad que puede generar en una determinada compra.

Para puntualizar los enfoques emotivos y racionales, las herramientas orientadas a temas como la información directa, elementos básicos del producto, precios, ahorros monetarios o, incluso, algunas promociones en las que se observe un beneficio real tangible o monetario, tienden a presentar un enfoque dado más hacia el consciente del consumidor, mientras que las herramientas basadas en la persuasión no directa, tales como publicidad subliminal, diseños gráficos, promociones aspiracionales y otros relacionados más con las emociones y con un menor esfuerzo analítico del consumidor, tienen un enfoque dirigido al subconsciente (Braidot, 2009).

Destacan acá los enfoques psicológicos de la racionalidad y la emotividad de las personas (Clonninger, 2003), donde, en función del enfoque que se aplique a la herramienta utilizada, pueden explotarse los elementos límbico, neocortesiano o, incluso, reptiliano en el consumidor, además de poder observar e investigar, inductivamente, los procesos sinápticos del comprador, reflejados en sus patrones de compra, tal y como sostiene Babbie (2000), al ser el primer enfoque la capacidad analítica y cognitiva del pensamiento del individuo y el segundo la actuación guiada únicamente por el elemento emocional de la persona.

En este punto se determina que el juego de pesos emotivos y racionales definen la decisión comercial y ambos deben ser vistos desde una aproximación humanista 
en su influencia, es decir, aplicarlos de forma que dignifiquen y beneficien al hombre dentro de su entorno comercial, puesto que los dos criterios administrados de forma correcta permiten generar una mayor lealtad en el consumidor.

La influencia y validez de la efectividad del uso de herramientas comerciales psicológicas en la venta de productos y su influencia en los patrones conductuales se observa en lo expresado por Schiffman y Kanuk (2005), quienes plantean lo siguiente:

Muchas de las teorías iniciales sobre el comportamiento del consumidor se basaron en la teoría económica, respecto a la idea de que los individuos actúan de manera racional para maximizar sus beneficios (satisfacciones) en la compra de bienes y servicios. En investigaciones posteriores se descubrió que los consumidores son igualmente propensos a realizar compras impulsivas y a dejarse influir no solo por familiares y amigos, anunciantes y modelos de roles, sino también por el estado de ánimo, la situación y la emoción. Todos estos factores se combinan para construir un modelo integral del comportamiento del consumidor, que refleje tanto los aspectos cognitivos como los emocionales en la toma de decisiones del consumidor. (p. 19)

Destacan, además, la observación del reflejo de los patrones neurales y sinápticos del consumidor, presentados en sus patrones cuantitativos de compra, es decir, la inducción investigativa mediante el uso de herramientas de medición de la conducta comercial de compra que, a su vez, permitan la medición simultánea de una variable adyacente, tal y como lo expresa García, B. (2005). Esta consiste en los procesos neurales y sinápticos, reflejados en la cuantificación del patrón de conducta del comprador, dado por la cantidad de compras y otros indicadores numéricos. Esto brinda una perspectiva clara de una posible medición neural sin la necesidad de técnicas mecanizadas o electrónicas, eso sí, enfocada a la observación de su reflejo en los patrones de compra.

\section{Conclusiones}

- Los patrones de conducta de compra de los consumidores son dados por la definición de los elementos racionales y emotivos del consumidor, los cuales a su vez determinan de forma directa la estructuración básica de la decisión de compra y son definidos en un juego de pesos y contrapesos de ambos criterios, proveídos por la generación de actividad mental, ligada a las regiones cerebrales utilizadas, los neurotransmisores generados y los procesos 
sinápticos de la persona, lo cual denota un concepto que podría definirse como humanismo neuroconductual.

- La conducta comercial de compra de los consumidores refleja, indudablemente, los procesos neurales dados en la mente de los clientes, mediante un proceso de investigación analítica inductiva, detalla la naturaleza de dichos procesos e indica la región cerebral de mayor uso en una determinada decisión de compra, tema que aunque presente una investigación complicada, puede verse reflejado en la estructuración básica de la decisión de compra, al definir que las variables utilizables y el efecto neural que generen son los definidores de dicha decisión. Se concluye, entonces, que una decisión emotiva contempla el uso del hemisferio derecho, una presinapsis o sinapsis y el cerebro límbico, mientras que las decisiones de compra racional parecen estar basadas en el hemisferio izquierdo, una postsinapsis y el cerebro neocortesiano.

- Las decisiones de compra, así como los patrones conductuales del consumidor, se ven definidos por el uso de las regiones límbica, neocortesiana y reptiliana del cerebro, en donde se plantea una relación entre análisis racional y factores emocionales del individuo, en función de los procesos sinápticos dados en el cliente, lo cual tiene también relación con la generación de transmisores neurales químicos, al establecer de forma clara que a medida que los químicos que desaceleren la sinapsis se incrementa, la racionalidad decae y se convierte, a su vez, en las decisiones humanas más fuertes, pero con menos proceso analítico; estos datos plantean la estructura fundamental de la conducta del consumidor.

- Se observa que las herramientas comerciales dirigidas a la explotación de temas ligados al análisis, por parte del cliente, tales como: precios, productos y elementos informativos, parecen denotar un efecto mayormente postsináptico y neocortesiano, mientras que las tácticas ligadas a aspiraciones, comunicación emotiva y demás elementos impulsivos tienen mayor ligamen a procesos presinápticos y límbicos, tema que se liga de igual forma al uso de los lóbulos cerebrales, donde lo visual influye en el occipital, lo físico afecta al lóbulo parietal y lo auditivo y olfativo influyen en el lóbulo temporal. Establecen así una mezcla de técnicas de influencia humana que afectan los sentidos del individuo en términos de su conducta comercial, analizables también en un contexto humanístico, siempre que se realicen en aras de dignificar a la persona.

- Si bien es cierto, los procesos neurales son únicamente mesurables por técnicas electrónicas y especializadas de mediciones craneales, se concluye que los procesos mentales y neurales son observables de manera inductiva en la conducta 
comercial, dados por la conducta cuantificable y por su análisis y estudio ligados a las herramientas y tácticas comerciales utilizadas, lo que demuestra que la estructuración teórica fundamental de la neuroconducta comercial se sustenta en los procesos neurales, la sinapsis neural, los neurotransmisores y las regiones cerebrales, los que a su vez deben ser analizados desde una óptica humanista e integral, de forma que se logren entender las razones de fondo en el accionar humano en el comercio y sus decisiones de compra.

\section{Referencias}

Alonso, J. y Grande, I. (2004). Comportamiento del consumidor. (5ta ed.) España: Esic Editorial.

Anderson, J. (2008). Redes neurales. México: Alfaomega.

Babbie, E. (2000). Fundamentos de la investigación social. México, D.F.: International Thomson Editores.

Braidot, N. (2009). Neuromarketing. ¿Por qué tus clientes se acuestan con otro si dicen que les gustas tú? Barcelona: Gestión 2000.

Cloninger, S. (2003). Teorías de la personalidad (3a ed.). México: Pearson Education.

Domínguez, A. y Muñoz, G. (2010). Métricas del marketing (2a ed.). Madrid: ESIC Editorial.

Esteban, A., Martín-Consuegra, D., Millán, A. y Molina, A. (2002). Introducción al marketing. Barcelona: Editorial Ariel S.A.

Flavian, G. y Gurrea, R. (2004). El estudio del comportamiento del consumidor en un entorno virtual. España: Universidad de Zaragoza.

García, B. (2005). Habilidades para el estudio de la ciencia económica. México: Facultad de Económica UNAM.

García, G. (2005). Investigación comercial. (2nda ed.) España: Esic Editorial.

Gerrig, R. y Zimbardo, P. (2005). Psicología y vida. (17a ed.). México: Pearson Education.

Hernández, J. (2007). Análisis de series temporales económicas. España: Esic Editorial.

Jensen, E. (2004). Cerebro y aprendizaje. Competencias e implicaciones educativas. España: Narcea S.A de Ediciones. 
Johnston, M. y Marshall, G. (2009). Administración de ventas. (9na ed.). México: Editorial Mc Graw Hill.

Keat, P. y Young, P. (2004). Economía de empresa. (4ta ed.). México: Pearson Education.

Kolb, B. y Whishaw, I. (2006/2008). Neuropsicología humana. (1era reimpresión). (5 ed.). Madrid, España: Editorial Médica Panamericana.

López, A. y Pérez-Llantada, M. (2005). Evaluación de programas en psicología aplicada. (Salud, Intervenciones sociales, deporte, calidad). Estados Unidos: Dykinson, S. L.

López, R. (2006). Cálculo de probabilidades e inferencia estadística con tópicos de Economía. (4 ed.). Venezuela: Universidad Católica Andrés Bello. Complutense.

Laboral. Un instrumento económico, jurídico para un humanismo del siglo XXI. España: Netbiblo. S.L.

Luelmo, M. (2012). La responsabilidad social corporativa en el ámbito del Derecho.

Malfitano, O., Arteaga, R., Romano, S. y Scínica, E. (2007). Neuromarketing. Cerebrando negocios y servicios. Buenos Aires: Ediciones Granica S.A.

Malhotra, N. (2004). Investigación de mercados. Un enfoque aplicado. México, D. F.: Pearson Education

Mollá, A., Berenguer, G., Gómez, M., y Quintanilla, I. (2006). Comportamiento del consumidor. Barcelona: UOC.

Pardo, A. (2013). Un desconocido en nuestra cabeza. Revista Dominical: Grupo Nación. Tomado desde: http://www.nacion.com/ocio/revista-dominical/ desconocidocabeza_0_1363463641.html

Renvoisé, P. y Morin, C. (2006). Neuromarketing. El nervio de la venta. Barcelona: Editorial UOC.

Sánchez, J. (2011). Estudio de la influencia de la personalidad en los patrones de compra y pago electrónicos del consumidor en Internet. Modelo de gestión del comportamiento virtual de los consumidores en el Valle Central de Costa Rica. Costa Rica: Universidad Fidélitas.

Santacolama, J. y Aguado, R. (2011). Economía y humanismo cristiano. Una visión alternativa de la actividad económica. Universidad de Deusto: Bilbao. 
Schiffman, L. y Kanuk, L. (2005). Comportamiento del consumidor. (8va ed.). México: Prentice Hall.

Solomon, M. (2013). Comportamiento del consumidor. (10a ed.). México: Pearson.

Sutil, L. (coord.). (2013). Neurociencia, marketing y empresa. España: Esic.

Thayer, R. (1998). El origen de los estados de ánimo cotidianos. El equilibrio entre la tensión, la energía y el estrés. Oxford University Press Inc. Nueva York. 